\title{
A systematic review and meta-analysis of the prevalence and predictors of anemia among children in Ethiopia
}

\author{
Alemu Gebrie ${ }^{1}$, Animut Alebel ${ }^{2}$
}

1. Department of Biomedical Science, School of Medicine, Debre Markos University, Debre Markos, Ethiopia. 2. Department of Nursing, College of Health Sciences, Debre Markos University, Debre Markos, Ethiopia.

\section{Email}

AA: animut.a23@gmail.com

\begin{abstract}
Background: Anemia is a wide-spread public health problem characterized by a decrease in hemoglobin concentration and/ or red blood cell volume below an established cut-off value. In developing countries including Ethiopia, about half of children are estimated to be anemic. Therefore, the purpose of this study was to determine the pooled prevalence of anemia and its predictor factors among children in Ethiopia.

Method: The studies were identified through explicit and exhaustive search of reputable databases (PubMed, Google scholar, Science Direct, EMBASE, Cochrane library, and the hand search of reference lists of previous prevalence studies to retrieve more related articles. Thirty-nine studies were selected based on a comprehensive list of inclusion and exclusion criteria. Data were extracted using a standardized and pre-tested data extraction checklist, and the analysis was done using STATA 14 statistical software. To assess heterogeneity, the Cochrane Q test statistic and I2 tests were used. In our analysis, considerable heterogeneity was observed. Therefore, a random effect meta-analysis model was used to estimate the pooled prevalence of anemia. Moreover, the predictor factors of anemia were examined.

Results: The forest plot of 39 included studies revealed that the overall pooled prevalence of anemia among children in Ethiopia was 34.4\% (95\% CI: 29.1, 39.7\%). Sub-group analysis showed that the highest anemia prevalence was observed in Somali Region with a prevalence of $49.4 \%$ (95\% CI: 20.9, 77.8). Also, anemia in children was found to be highest in the age group of less than five years (45.2, 95\% CI: 39.6,50.8). Low literacy of families: 1.3 (95\% CI: 1.1, 1.7), low family socioeconomic status: 1.9 (95\% CI: 1.1,3.01.3), having housewife mothers or with no job: 1.5 (95\% CI: 1.4, 1.9) and rural residence: 3.3 (95\% CI: 1.7,6.1) were found to be predictors of anemia among children.

Conclusion: In this study, one in three children were anemic in Ethiopia. It is a moderate public health problem in children in this study. Low literacy, low socioeconomic status as well as rural residence of the families and helminthic infection of the children were found to be predictors of anemia in the children. Community and school-based interventions should be strengthened to improve the problem.
\end{abstract}

Keywords: Anemia; prevalence; predictors; children,; Ethiopia; systematic review; meta-analysis.

DOI: https://dx.doi.org/10.4314/ahs.v20i4.59

Cite as: Gebrie A, Alebel $A$. A systematic review and meta-analysis of the prevalence and predictors of anemia among children in Ethiopia. Afri Health Sci. 2020;20(4):2007-21. bttps://dx.doi.org/10.4314/ahs.v20i4.59

\section{Background}

Anemia is a wide-spread public health problem characterized by a decrease in hemoglobin concentration and/ or red blood cell volume below an established cut-off value resulting in an impaired capacity of the blood to

\section{Corresponding author:}

Alemu Gebrie,

Department of Biomedical Science,

School of Medicine, Debre Markos University,

Debre Markos, Ethiopia.

P.O. Box 269

Email: alemugebrie2@gmail.com transport oxygen to the body tissues ${ }^{1,2}$. Worldwide, it is estimated that more than 2 billion people are suffering from anemia. Although it occurs at all population, anemia is more pervasive in pregnant women and school aged children ${ }^{3,4}$. In developing countries, about half of children are estimated to be anemic, and it is incommodious in sub-Saharan African Countries like Kenya 48.9\% 5, Mali 55.8\% ${ }^{6}$ and Tanzania 79.6\% $\%^{7}$. As per the 2016 report of Ethiopian Demographic and Health Survey (EDHS), more than half $(57 \%)$ of Ethiopian children aged 6-59 months are anemic. The figure is higher than that reported in EDHS 2011 (44\%), which is above the cut off value $(40 \%)$ of the World Health Organization 
(WHO) category of anemia as a severe public health problem $^{8,9}$. The EDHS 2016 report also showed that mild, moderate and severe anemia accounted for $25 \%$, $29 \%$ and 3\%, respectively, and children in rural areas are at a higher risk to be anemic than children in urban areas $(58 \% \text { vs } 49 \%)^{10}$.

Anemia is the result of multiple risk factors that vary across geographical areas, and coexist together with deficiencies of other micronutrients, of which iron deficiency is the leading $(50 \%)$ predictor ${ }^{11,12}$. Studies unveiled that socioeconomic factors like illiteracy ${ }^{13}$, gender norms ${ }^{14}$, and poverty ${ }^{15}$; infectious diseases such as intestinal helminths, tuberculosis and malaria ${ }^{7,16}$ are risk factors for anemia. In addition, genetic problems, digestive abnormalities, absorption difficulties as well as the deficiencies of other essential micronutrients including folic acid, vitamin B12 and vitamin A contribute to the occurrence of anemia ${ }^{17}$.

Anemia results in several acute and chronic health problems on children. It impairs their learning performance, psychomotor and cognitive maturity, behavioral and physical growth increasing the risk of morbidity and mortality ${ }^{2,18}$. In addition, anemia is related to poor intelligent quotient, and it also affects the capacity of language coordination in children. Generally, anemia is one of the public health challenges for the country and it is an indicator of poor health status ${ }^{3,4}$.

Integrated into the ordinary childhood health services and community based nutritional interventions, the Ethiopian Ministry of Health has been implementing anemia prevention programs to control childhood anemia. Moreover, the ministry has regularly performed children de-worming movements since $2004{ }^{19}$. Despite efforts to combat anemia in children in the last two decades, it remains a major health problem of children in the country ${ }^{9}$. Because of the presence of complex and multifactorial risk factors for anemia and the potential interactions among them, the implementation of highly integrated strategy for prevention and control of anemia in children is imperative ${ }^{20}$.

In different parts of Ethiopia, several independent and fragmented studies as well as a review study ${ }^{9,21-59}$ were carried out in children to assess the prevalence and associated factors of anemia, but there was a great variation and inconsistency among the findings of the studies. Also, the previous review study did not include relevant studies exhaustively, and did not review more important predictors of anemia among children. In addition, important statistical analyses were missing in the review. Hence, the aim of this systematic review and meta-analysis was to review and determine the pooled prevalence and predictor factors of anemia among children in Ethiopia. The findings from the present study will help for policy makers, program planners, guardians or parents, clinicians as well as concerned stakeholders to give more emphasis for childhood anemia in the country. The study will also be of paramount importance for contemporary researchers to be contentedly engaged in related topics. The systematic review question is: What is the best available evidence on the prevalence and predictors of anemia among children in Ethiopia?

\section{Methods}

\section{Study design and literature searching strategy}

We followed the methods of Gebrie et al., $2018^{60}$. We carried out a systematic review and meta-analysis of eligible published and unpublished studies to determine the pooled prevalence of anemia and its predictors among children in Ethiopia. The Preferred Reporting Items for Systematic Reviews and Meta-Analyses (PRISMA) ${ }^{61}$ guideline was followed for the scientific rigor of the study. The studies for this review were retrieved through reproducible and comprehensive electronic searching of major reputable databases (PubMed, Google scholar, ScienceDirect, EMBASE, Cochrane library). We have also done manual searching of the reference lists of already identified relevant articles so as to retrieve more eligible studies. In addition, we used the "related articles" option of PubMed to search more relevant articles. Moreover, an open search in national and Ethiopian Ministry of Health websites were done to identify anemia prevalence among children not reported in scientific journals. The two authors (AG, AA) performed the search independently based on the following key terms: (1) population (preschool, children, schoolchildren, school aged, childhood, schooler, preadolescent); (2) outcome (anemia, anaemia, hematologic parameter, hematologic profile, micronutrient deficiency; (3) study design (prevalence, cross-sectional, epidemiology, observational, longitudinal study); and (4) location (regions of Ethiopia and Ethiopia). The terms were used both separately and in combination with the help of the Boolean operator like "AND", "OR", or "NOT" (see additional file 1). We have meticulously analyzed the appropriateness of the searching terms before performing the search in order to identify the relevant studies. The literature search was limited to human study category and English language. However, the literature search for published articles was not restricted by time, and all the studies up to January 03/2018 were considered to be included in this systematic review and meta-analysis. The articles were searched, organized and extracted from September, 2017 to January 03/2018. Also, End- 
Note X7 reference manager has been used to manage the literature retrievals since the inception of the study.

\section{Study selection \\ Inclusion criteria}

The two authors independently and meticulously appraised the contents of each of the identified articles (AG and AA). The studies which met the following criteria were considered eligible for inclusion in the study. The retrievals were appraised for inclusion in the final review by using their titles, abstracts, and then by reviewing full text papers.

Population: Studies carried out in children

Study area: Those studies conducted only in Ethiopia.

Study design: Original studies and government surveys which reported the prevalence and predictor factors of anemia among children in Ethiopia were included.

Language: only studies reported in English language were included.

Publication condition: Studies which meet the eligibility criteria were included regardless of their publication status (published, unpublished and grey literature, etc.)

\section{Exclusion criteria}

The two reviewers (AG and AA) performed the selection of the studies independently and blindly after thorough screening of the abstracts and the full texts of the studies. Those articles having methodological problems were excluded. Any disagreements during review process were resolved by consensus and when the disagreements continue after discussion, a third person was consulted to finally settle the discrepancy. The processes of identifying, screening and including or excluding records were done using the PRISMA ${ }^{61}$ flow diagram guideline.

\section{Data abstraction and quality assessment}

The two authors abstracted the required data using a pilot-tested and prepared data abstraction tool. The extracted data included: first author, area where the study was conducted, study design, publication year, sample size, response rate, mean hemoglobin level, and prevalence of anemia among children. Any sort of disagreement during the data extraction were resolved by discussion as well as through involvement of the third person (AZ).

The authors employed the Newcastle-Ottawa quality assessment tool Scale adapted for cross-sectional studies in order to assess the qualities of the studies ${ }^{62}$. This standardized tool contains three main indicators regarding the methodological qualities, the comparability and the statistical analyses of articles. The qualities of the studies were evaluated by using the following indicators; those with medium (fulfilling $50 \%$ of quality assessment criteria) or high quality ( $\geq 6$ out of 10 scales) were included in the study. The assessment results were determined taking the mean score of the two authors.

\section{Outcomes of interest of the study}

The foremost outcome of the current study was prevalence of anemia among children. According to WHO $2001^{63}$, anemia among children was defined as a hemoglobin concentration of less than $11 \mathrm{~g} / \mathrm{dL}$ for ages less than 5 years, hemoglobin concentration of less than $11.5 \mathrm{~g} / \mathrm{dL}$ for ages 5-11 years, and hemoglobin concentration of less than $12 \mathrm{~g} / \mathrm{dL}$ for ages $12-14$ years. As per WHO 2011 guideline ${ }^{64}$, anemia was also defined as hemoglobin concentration less than $11 \mathrm{~g} / \mathrm{dl}$ for children less than 5 years old, hemoglobin concentration less than $11.5 \mathrm{~g} / \mathrm{dl}$ for children 5-11.9 years old, and hemoglobin concentration less than $12 \mathrm{~g} / \mathrm{dl}$ for children 12-14.9 years old. The studies included in this review operationalized and defined anemia as per WHO guidelines, some of them adjusting for altitude. The second outcome of this study was associated factors of anemia among the study subjects. The prevalence was obtained by dividing the number of children who are anemic to the total number of children included in the study (sample size) then multiplied by 100 . The association between anemia and the predictors were quantified by odds ratio. The odds ratio was calculated from the two by two table reports of the original studies.

\section{Heterogeneity and publication bias}

Publication bias and heterogeneity were checked using the Egger's and Begg's tests. A p-value of less than 0.05 were considered to declare statistical significance of publication bias and heterogeneity. The heterogeneity of studies was also assessed using I 2 test statistics. The I2 test statistics of $25 \%, 50 \%$, and $75 \%$ was considered as low, moderate and considerable heterogeneity, respectively. For the test results exhibited heterogeneity, random effect model was used as a method of analysis.

\section{Data analysis/synthesis of results}

After the relevant data had been extracted from the studies by using Microsoft Excel 2016 format, the authors then analyzed the results by using STATA version 14.0 (STATA Corporation, College Station Texas) software. 
The original studies were summarized and presented by using a table and a forest plot. The authors computed the standard error of prevalence of anemia for each original study by using binomial distribution formula. We explored the potential heterogeneity among the reported prevalence of the studies using I2 test and Cochrane $Q$ statistics ${ }^{65} / \mathrm{a}>$. Since the test statistics revealed that there was a considerable heterogeneity ${ }^{66}$ among the studies ( $\mathrm{I} 2=99.5 \%, \mathrm{p}<0.001)$, a random effects model was used to estimate the Der Simonian and Laird's pooled effect. We have also undertaken univariate meta-regression analysis taking publication year of the studies and the sample size to detect the potential source(s) of variation but both of them were found to be statistically insignificant, $(p>0.05$ and $p>0.05$ respectively). Potential publication bias was also objectively examined using Egger's weighted correlation and Begg's regression intercept tests at $5 \%$ significant level respectively ${ }^{67,68}$. The test results showed that there is no significant publication bias ( $\mathrm{p}>0.05)$. the funnel plot also supports subjectively the absence of publication bias (see additional file 2). In addition, to minimalize the random variations between the point estimates of the original studies, subgroup analysis was carried out based on region of studies, study settings and age group of children.

\section{Results \\ Search results}

From the beginning, we retrieved a total of 570 records through manual and electronic searches. The electronic search was performed through database search of MEDLINE/PubMed, Google scholar, science direct, EMBASE, Cochrane Library and reference lists of previous related studies to retrieve more related articles. Because of duplications in the records, 422 of them were removed from the retrievals. After the authors assessed the titles and abstracts of the records, the remaining 148 retrievals, 79 records were excluded for they were not relevant for this review in terms of outcome the study is interested. Then, 69 full text were considered and assessed for eligibility based on the preset eligibility criteria. Finally, 39 studies were considered to be relevant and included in this systematic review and quantitative meta-analysis (Figure 1).

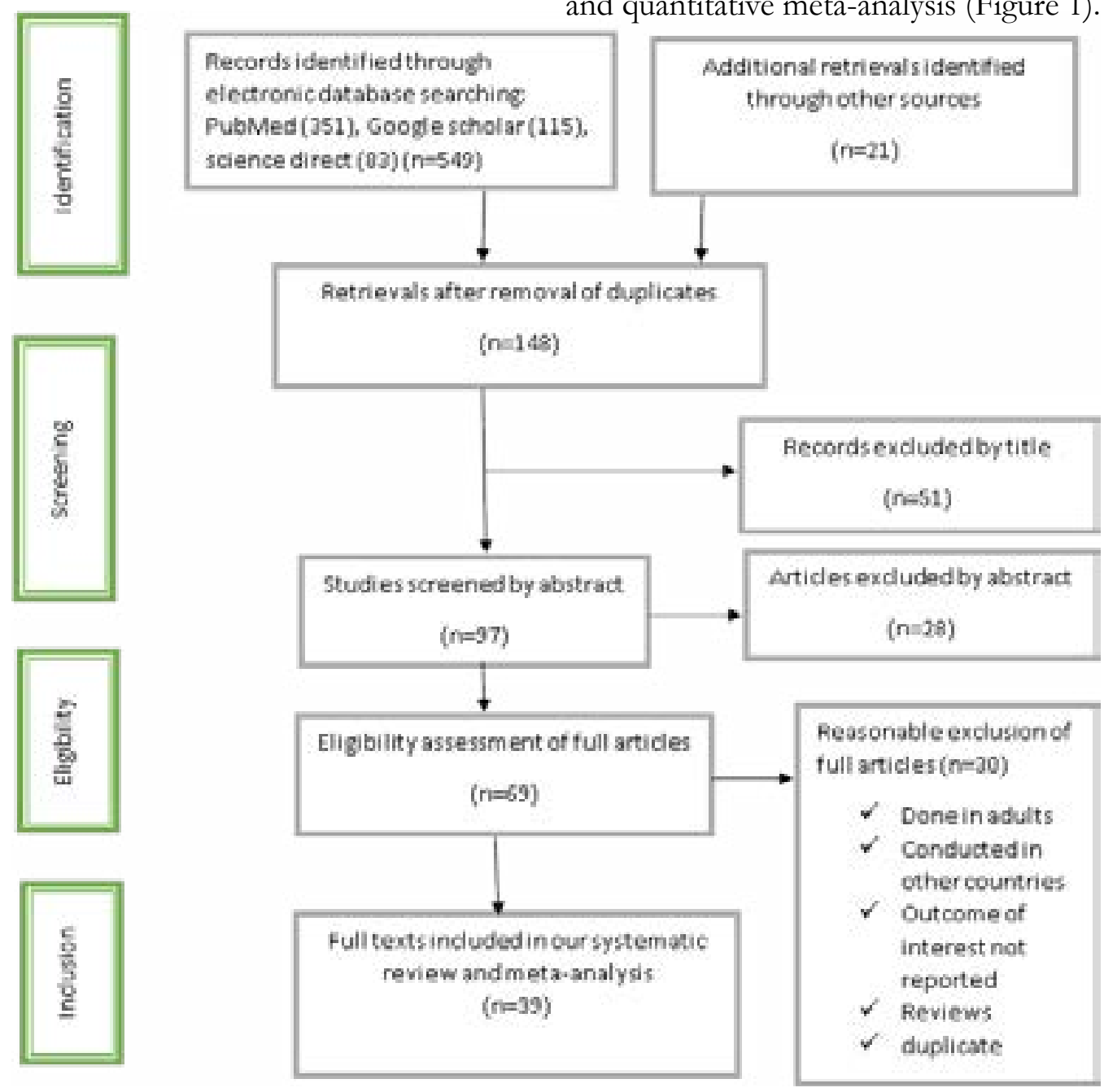

Figure 1: Flow chart diagram and PRISMA checklist describing selection of studies for the systematic review and meta-analysis of prevalence and predictors of anemia among children in Ethiopia, 2018 (identified, screened, eligible and included studies). Articles may have been excluded for more than one reason. 
From a total of 69 full text studies accessed, we removed nine of them because the outcome of interest was not mentioned and/or they were conducted in other nations which are not the location of interest of the review; these studies were conducted in Africa ${ }^{69,70}$, Tanzania $^{71,72}$, Malawi ${ }^{73}$, Nigeria ${ }^{74-76}$ and $\mathrm{Mali}^{77}$. In addition, 20 full text articles ${ }^{78-97}$ that have been carried out from different parts of Ethiopia were excluded because their outcome measures were not prevalence of anemia in children, and they were conducted in the adult population which is not the population of interest of the this meta-analysis. Moreover, one full text article ${ }^{98}$ was excluded because of duplicated publications of our result of interest in different journals (see additional file 3).

\section{Description of original studies}

Table 1 presents the descriptive summary of the characteristics of 39 studies included in this systematic review and meta-analysis. All of the studies are cross sectional by design (community based, school based and health institution based, see additional file 4). The studies were conducted in different regions of Ethiopia with a sample size that ranges from 64 in JUSH (Jimma University
Specialized Hospital), Oromia region to 9267 in EDHS 2016. The eligible studies have been carried out since 1999. In the present systematic review and meta-analysis, a total of 64,727 children were enrolled to estimate the pooled prevalence of anemia in the subjects.

The 39 studies have been done in almost all regions of Ethiopia: two of the studies were conducted in Addis Ababa; nine in Amhara region, one in Afar region, two in Harari region, one in Benishangul region, eight in Oromia region, one in Oromia and Tigray regions, three in Somali region, three in Tigray region, three from Southern Nations, Nationalities and peoples' region (SNNPR) and six nationwide survey studies three of which are EDHSs. The highest prevalence of anemia $(72 \%)$ was observed in Somali Region (Gode Zone) in 2017. On the other hand, the lowest prevalence (7.6\%) of anemia was reported in Amhara Region (Bahirdar and Mecha district schools) in the same year. Some of the studies also reported mean hemoglobin lebel. Besides, the primary studies included in this review had a response rate that ranges from $51.8 \%$ to $100 \%$, and virtually all of the studies had good response rate (Table 1). 


\begin{tabular}{|c|c|c|c|c|c|c|c|c|c|}
\hline Region & Area & Author & Publication year & $\begin{array}{l}\text { Sample } \\
\text { size }\end{array}$ & $\begin{array}{l}\text { Response rate } \\
(\%)\end{array}$ & $\begin{array}{l}\text { Quality } \\
\text { (10 pts) }\end{array}$ & score & $\begin{array}{l}\text { Mean } \\
\mathrm{Hb}^{*} \text { (in } \\
\mathrm{g} / \mathrm{dl} \text { ) }\end{array}$ & $\begin{array}{l}\text { Prevalence of } \\
\text { anemia }\end{array}$ \\
\hline \multirow[t]{2}{*}{ Addis Ababa } & Yekatit 12 hospital & Debasu et al ${ }^{41}$ & 2015 & 106 & 100 & 6 & & 12.2 & 18.9 \\
\hline & Zewditu hospital & Mihiretie et al ${ }^{36}$ & 2015 & 180 & $\mathrm{~N} / \mathrm{R}$ & 7 & & - & 22.2 \\
\hline Afar & Amibara woreda & Deribew et al ${ }^{55}$ & 2013 & 387 & 100 & 7 & & 9.67 & 31.8 \\
\hline \multirow[t]{9}{*}{ Amhara } & Libo Kemkem and Fogera & Herrador et al ${ }^{52}$ & 2014 & 764 & 85.9 & 8 & & - & 30.9 \\
\hline & Durbete & Alelign et al ${ }^{23}$ & 2015 & 384 & 95.3 & 7 & & - & 10.7 \\
\hline & Wag-Himra & Woldie et al ${ }^{47}$ & 2015 & 347 & 97 & 7 & & - & 66.6 \\
\hline & Gondar & Enawgaw et al ${ }^{34}$ & 2015 & 264 & 99.6 & 8 & & - & 16.2 \\
\hline & Amhara & Gashu et al ${ }^{35}$ & 2016 & 628 & 628 & 6 & & - & 13.6 \\
\hline & Gondar university hospital & Geletaw et al ${ }^{33}$ & 2017 & 222 & 91.7 & 6 & & 11.5 & 42.8 \\
\hline & Gondar town & Getaneh et al $^{45}$ & 2017 & 523 & 96.5 & 8 & & - & 15.5 \\
\hline & BDR and Mecha district & Feleke et al $^{42}$ & 2017 & 2372 & 94.5 & 6 & & 11.6 & 7.6 \\
\hline & Debre birhan & Engidaye et al ${ }^{58}$ & 2017 & 432 & 100 & 7 & & - & 28.5 \\
\hline Benishangul & Pawe General Hospital & Birhanu et al ${ }^{32}$ & 2017 & 377 & 100 & 6 & & 11.7 & 40.3 \\
\hline \multirow[t]{2}{*}{ Harari } & Babile & Teji et al 22 & 2017 & 547 & 91 & 5 & & - & 32 \\
\hline & Hiwot Fana hospital & Teklemariam et al ${ }^{38}$ & 2015 & 103 & $\mathrm{~N} / \mathrm{R}$ & 7 & & 10.7 & 54.4 \\
\hline \multirow[t]{6}{*}{ Nation wide } & Ethiopia & Habte et al ${ }^{29}$ & 2013 & 8260 & 100 & 6 & & 10.7 & 50.3 \\
\hline & Ethiopia & Reithinger et al ${ }^{30}$ & 2013 & 6054 & 92 & 7 & & - & 36.4 \\
\hline & malaria endemic arias & Birhanu et al ${ }^{21}$ & 2017 & 763 & 73.1 & 8 & & 12.8 & 17.3 \\
\hline & Nation wide & EDHS $^{57}$ & 2005 & 4138 & $\mathrm{~N} / \mathrm{R}$ & $\mathrm{N} / \mathrm{A}$ & & - & 53.5 \\
\hline & Nation wide & EDHS $^{56}$ & 2011 & 9157 & 93.4 & $\mathrm{~N} / \mathrm{A}$ & & - & 44.2 \\
\hline & Nation wide & EDHS $^{9}$ & 2016 & 9267 & 88 & $\mathrm{~N} / \mathrm{A}$ & & - & 56.9 \\
\hline \multirow[t]{8}{*}{ Oromia } & JUSH & Gedefaw et al ${ }^{31}$ & 2013 & 234 & 100 & 7 & & 14.1 & 23.1 \\
\hline & JUSH & Muluneh et al ${ }^{51}$ & 2009 & 64 & 94.1 & 5 & & 10.5 & 21.9 \\
\hline & Jimma Town & Assefa et al ${ }^{25}$ & 2014 & 404 & 95.6 & 7 & & 11.6 & 37.6 \\
\hline & Jimma Town & Desalegn et al ${ }^{26}$ & 2014 & 586 & 95 & 8 & & - & 43.7 \\
\hline & Kersa district & Mesfin et al ${ }^{24}$ & 2015 & 1755 & $\mathrm{~N} / \mathrm{R}$ & 8 & & 12.6 & 27.1 \\
\hline & Butajira & Taye et $\mathrm{al}^{37}$ & 2015 & 739 & 73.4 & 7 & & 11.8 & 34.8 \\
\hline & Jimma Health Center & Seble et al ${ }^{53}$ & 2016 & 130 & 51.8 & 8 & & - & 33.1 \\
\hline & Adami Tullu & Gari et al ${ }^{40}$ & 2017 & 6112 & $\mathrm{~N} / \mathrm{R}$ & 8 & & 11.6 & 32.6 \\
\hline Oromia \& Tigray & Babile and Enderta & Roba et al ${ }^{46}$ & 2016 & 216 & 98.2 & 7 & & 11.4 & 53.7 \\
\hline \multirow[t]{3}{*}{ SNNP } & Gurage & Birmeka et al $^{48}$ & 2017 & 680 & 97.4 & 5 & & - & 31.3 \\
\hline & Wolaita Zone & Tiku et al ${ }^{44}$ & 2018 & 404 & $\mathrm{~N} / \mathrm{R}$ & 8 & & - & 51.4 \\
\hline & 30 schools & Grimes et al $^{43}$ & 2017 & 3729 & 99.4 & 7 & & - & 23 \\
\hline \multirow[t]{3}{*}{ Somali } & Filtu & Gutema et al ${ }^{28}$ & 2014 & 355 & 100 & 8 & & 12.4 & 23.7 \\
\hline & Gode zone & Guled et al $^{49}$ & 2017 & 397 & 100 & 6 & & 9.7 & 72 \\
\hline & Kebribeyah refugee & Jemal et al $^{50}$ & 2017 & 399 & 90.7 & 6 & & - & 52.4 \\
\hline \multirow[t]{3}{*}{ Tigray } & $\begin{array}{l}\text { Mekele, Quiha and } \\
\text { Aynalem }\end{array}$ & Adish et al ${ }^{54}$ & 1999 & 2080 & 88 & 5 & & - & 42 \\
\hline & Mekele & Mahmud et al ${ }^{39}$ & 2013 & 600 & 100 & 6 & & 13.2 & 11 \\
\hline & Kilte Awulaelo & Gebremedhin et $\mathrm{al}^{27}$ & 2014 & 568 & 100 & 7 & & 11.5 & 37.3 \\
\hline
\end{tabular}

Regarding the publication status of the studies: only one 58 of the 39 studies is yet to be published. Also, three of the studies ${ }^{9,56,57}$ are EDHS studies. However, the rest of the studies included in the current meta-analysis were retrieved by exhaustive and reproducible search from reputable databases such as PubMed. The authors meticulously appraised all the studies before review and analysis, and the included articles were confirmed fit for their quality i.e. quality score ranging from 5-8 out of 10 marks.

\section{Meta-analysis and meta-regression}

In this meta-analysis, a forest plot (Figure 2) was used to estimate the pooled effect size and the effect of each study with their respective confidence interval (CI) in order to provide a visual summary data. Herein, the for- est plot of 39 included studies depicted that the overall pooled prevalence of anemia among children in Ethiopia was 34.4\% (95\% CI: 29.1, 39.7\%). Detected by I2 statistic $(\mathrm{I} 2=99.5$, $\mathrm{p}$ value $<0.001)$, we observed considerable heterogeneity 66 across the included studies. As a result, we employed the DerSimonian and Laird random-effects model to estimate the overall pooled prevalence of anemia among children since the model gives more conservative effect size. Taking publication year and sample size of the studies as potential factors associated with the prevalence variation, we performed univariate meta-regression analysis to determine the likely sources for the variation. However, neither of them is statistically significant for the variation (Table 2). In addition, Egger's and Begg's tests revealed that there is no statistically significant publication bias, $(p>0.05)$ and $(p>0.05)$, respectively. 


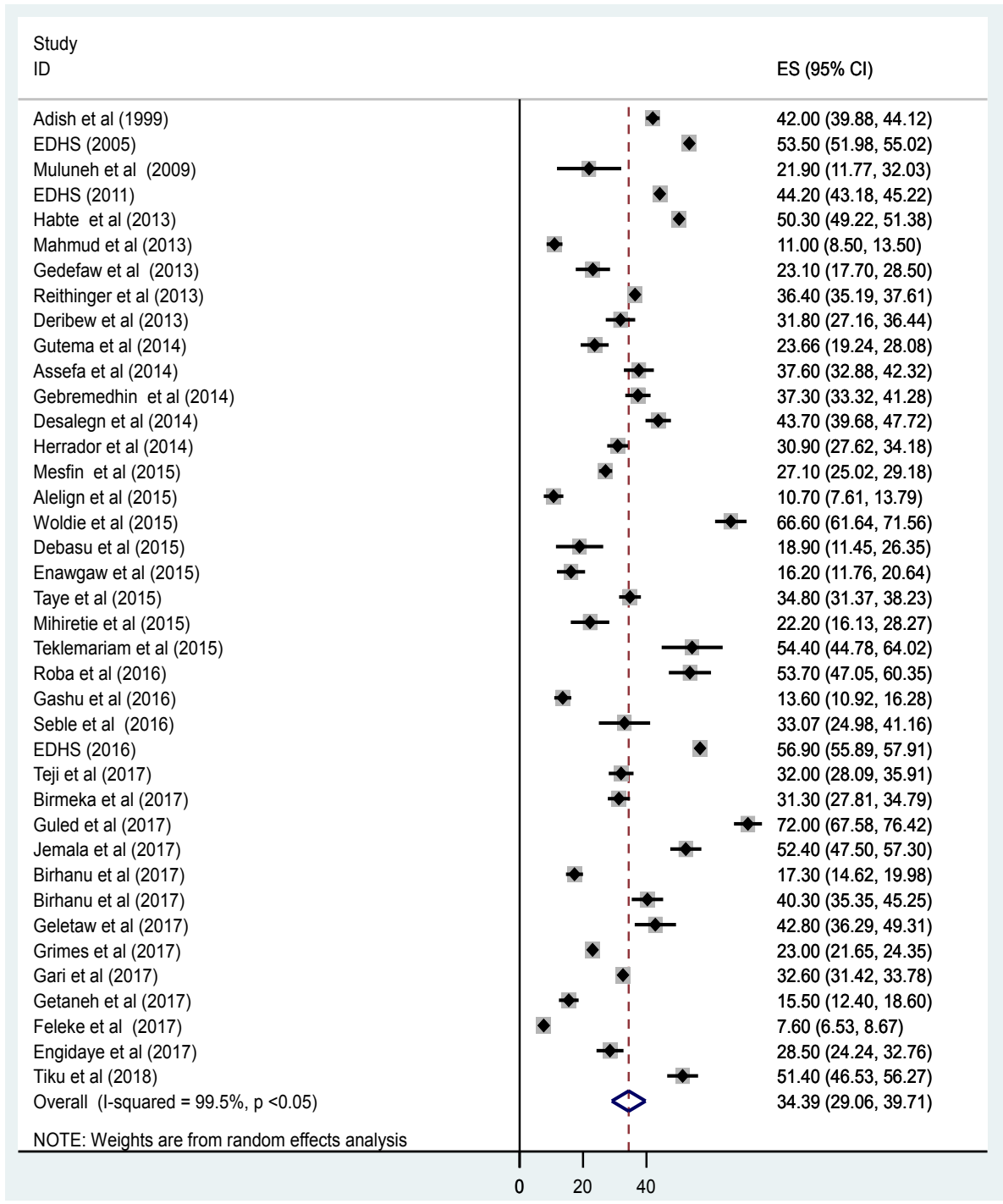

Figure 2 Forest plot of the pooled prevalence of anemia among children in Ethiopia, 2018

Table 2. Related factors with the heterogeneity of anemia prevalence among children in Ethiopia in the meta-analysis (univariate meta-regression), 2018

\begin{tabular}{ccc}
\hline Variables & Coefficient & P-value \\
\hline Publication year of studies & -1.4061 & 0.351 \\
Sample sizes of the studies & 0.0012186 & 0.603 \\
\hline
\end{tabular}

\section{Sub-group analysis}

Based on the region and the setting where the studies were conducted as well as the age group of children, we carried out subgroup analyses to assess the possible sources of heterogeneity. The result showed that the highest prevalence of anemia among children was observed in Somali Region with a prevalence of 49.4 $\%$ (95\% CI: 20.9, 77.8) followed by nationwide studies, 43.2 (95\% CI: 35.1, 51.2). But, the prevalence of anemia in the subjects was the least in Addis Ababa followed by Amhara region, 25.7 (95\% CI: 15.9, 35.5), as compared to all other regions 21.4 (95\% CI: 17.7, 25.1) (Table 3). Regarding the study settings, the prevalence of childhood anemia was relatively higher in studies which have been conducted in the community, 40.6 (95\% CI: 35.4, 45.9) as compared to those studies carried out in health institution and school settings (Table 3). Also, anemia in children was found to be highest in the age group of less than five years (45.2, 95\% CI: 39.6,50.8) (Table 3). 
Table 3. Results from subgroup analysis of the prevalence of anemia among children in Ethiopia, $2018(n=39)$

\begin{tabular}{|l|l|l|l|l|l|}
\hline \multirow{3}{*}{ Variables } & Characteristics & No studies & Prevalence with 95\% & $\mathbf{I}^{2}$ & p-value \\
\hline \multirow{5}{*}{ By region } & Addis Ababa & 2 & $20.9(16.2,25.6)$ & & \\
\cline { 2 - 6 } & Amhara & 9 & $25.7(15.9,35.5)$ & $0.0 \%$ & $=0.501$ \\
\cline { 2 - 6 } & Oromia & 8 & $32.3(28.4,36.2)$ & $99.0 \%$ & $<0.001$ \\
\cline { 2 - 6 } & Somali & 3 & $49.4(20.9,77.8)$ & 90.9 & $<0.001$ \\
\cline { 2 - 6 } & Others & 11 & $36.8(29.2,44.4)$ & 99.1 & $<0.001$ \\
\cline { 2 - 6 } & Nationwide & 6 & $43.2(35.1,51.2)$ & 98.4 & $<0.001$ \\
\hline \multirow{5}{*}{ By setting } & School based & 9 & $34.1(28.8,39.3)$ & 99.6 & $<0.001$ \\
\cline { 2 - 6 } & Health institution & 10 & $34.0(22.5,45.4)$ & $98.8 \%$ & $<0.001$ \\
\cline { 2 - 6 } & Community based & 20 & $40.6(35.4,45.9)$ & $97.1 \%$ & $<0.001$ \\
\hline \multirow{5}{*}{ By age group } & $<$ Five years & 14 & $45.2(39.6,50.8)$ & 99.3 & $<0.001$ \\
\cline { 2 - 6 } & $>$ Greater than five & 13 & $25.0(18.8,31.2)$ & 99.2 & $<0.001$ \\
\cline { 2 - 6 } & All age group & 12 & $31.8(19.6,44.1)$ & 98.8 & $<0.001$ \\
\hline
\end{tabular}

\section{Predictors of anemia among children}

The authors did comprehensively review and meta-analyze the predictors of anemia among the study subjects using nineteen meta-analyzable studies 21, 23-28, 34, 36, 37, $40-43,45-47,49,50$ from the relevant articles included in the current study. Sex of the children, family educational status, family occupation, family income, residence and helminthic infection were found to be worth reviewing and meta-analyzable. Except sex of the children, all the predictors revealed statistically significant association with anemia among children in Ethiopia (Table 4). The authors also performed sensitivity analysis for each of the factors, and none of the studies showed significant difference.

The pooled estimate of fourteen studies showed that male children were 1.1 times more likely to be anemic than their female counterparts, odds ratio 1.1 (95\% CI:
1.0,1.3) (Table 4). Those children whose families are illiterate (not educated) were 1.3 times more likely to be anemic as compared to those whose families are literate, odds ratio 1.3 (95\% CI: 1.1, 1.7) (Table 4). In addition, those children whose mothers were housewives or with no job were 1.5 times more likely to be anemic as compared to those whose mothers had different types of jobs, odds ratio 1.5 (95\% CI: 1.4, 1.9) (Table 4).8). Although there has been no similar study for comparison in the country, the 2016 Ethiopian demographic and health survey (EDHS) report revealed a higher (56.9\%) prevalence of anemia among children in the country. Sampling and study period could be the possible reasons for the difference in the results. Even though the EDHS was conducted in a nationally representative sample of 9267, this meta-analysis included studies which have been conducted since 1999 with a total of 64,727 children.

Table 4. Odds ratio of the associations between anemia and its purported associated predictor factors among children in Ethiopia, 2018

\begin{tabular}{|l|l|l|l|}
\hline Variables & OR (95\% CI) & $\mathbf{I}^{\mathbf{2}}$ & P-value \\
\hline Sex & $1.13(0.99,1.28)$ & $49.1 \%$ & 0.019 \\
\hline Family education & $1.34(1.07,1.67)$ & $67.9 \%$ & 0.001 \\
\hline Family occupation & $1.46(1.14,1.88)$ & $0.0 \%$ & 0.608 \\
\hline Family income & $1.86(1.14,3.01)$ & $92.8 \%$ & 0.000 \\
\hline Residence & $3.25(1.72,6.13)$ & $80.8 \%$ & 0.000 \\
\hline Helminthic infection & $2.52(1.31,4.86)$ & $93.7 \%$ & 0.000 \\
\hline
\end{tabular}


Sub-group analyses results in this study revealed that the prevalence of childhood anemia substantially varied across regions of Ethiopia, in study settings and age group. The highest anemia prevalence among children was observed in Somali region (49.4\%) whereas anemia was less prevalent in Addis Ababa (20.9\%) and Amhara region $(25.7 \%)$. The variation in the prevalence of anemia among the regions in Ethiopia could partially be due to the difference in the economic, sociodemographic and dietary difference among the regions. Also, the difference in study numbers included in each category (region) might also be attributed for the variation. In addition, the prevalence of anemia was relatively higher in those studies conducted in the community settings than health institutions or schools. This could possibly be due to a low nutritional intervention coverage to reduce anemia prevalence. Finally, anemia in children was found to be higher in the age group of less than five years. This finding was in line with findings in other related studies ${ }^{99-102}$. This could be because of the increased growth requirements in children under the age of five ${ }^{102}$. This suggests that the efforts to prevent and control anemia need to address preferentially most vulnerable age groups of children, under five years of age.

This review showed that the prevalence of anemia varied according to some predator factors from children and their families showing statistically significant variations for some factors and not for others. We have found that the magnitude of anemia does not vary with the gender of children. However, the educational status of children's families was a statistically significant predictor for the occurrence of anemia in children. Those children whose parents had no education were more likely to be anemic as compared to parents with primary educational status and above. This is congruent with a study done in Kenya ${ }^{103}$ and Bangladesh ${ }^{104}$. The reason could be explained that as the educational status of parents increases, so do their economic status and nutritional diversity. This results in an improved feeding practice and better health care of the children ${ }^{105}$, ${ }^{106}$. Children from low household income families were more likely to be anemic as compared to those children from moderate and high-income families. This finding is concordant with the study conducted in Brazil ${ }^{107}$ and in poor provinces of Qinghai and Ningxia from rural China ${ }^{108}$. The reason could be because of the fact that parents of low household income may not secure balanced and nutrient-rich food stuffs and children's diet is usually monotonous ${ }^{109-111}$.

Moreover, the pooled results of five studies revealed that children from rural areas were 3.25 times more likely to be anemic than their urban counterparts. This finding is in harmony with what was reported by EDHS 2016 ? The reason could possibly be pertaining to inadequate information about healthy diet feeding, and other economic factors that could cause anemia in rural communities. Lastly, children infected with helminths are more likely to be anemic as compared to those non-infected ones. This is in trajectory with the studies conducted in Tanzania and Nigeria ${ }^{112}$. The reason could be due to the fact that helminths infection causes loss of appetite, nutrition competition, feeding problem and red blood cell destruction in children. In addition, the parasites also result in impaired nutrient absorption by directly damaging the intestinal mucosal cells ${ }^{113,114}$.

\section{Strengths and limitations of the study}

This study has a sort of strength in that it uses multiple databases not to miss any eligible study. Data extraction was also done reproducibly using a preset and pretested checklist so as to minimize errors that could affect the estimate. This systematic review and meta-analysis also included studies from different regions of the country, both published and unpublished articles. However, the study is not free from potential limitations, it is restricted to articles published in English language for example. In addition, since meta-analysis uses aggregated group data by its nature, other confounding factors which could affect anemia were not proscribed. This may have affected the estimate. Also, the articles included in this review are weak to establish causal relationship between the associated factors and the outcome for they are cross sectional by design. As a result, the results of this met-analysis is helpful if interpreted considering both inherent limitations of the original studies and the current meta-analysis. .

\section{Conclusion}

Over one third of children suffer from anemia and it is associated with low literacy, low socioeconomic status as well as rural residence of the families and helminthic infection of children. However, we did not find gender of the children as a statistically significant predictor of anemia among the children. Hence, anemia is a moderate public health problem in children in this study. The observed magnitude of anemia is likely to affect the intellectual potential and overall health of the children. Relevant community and school-based interventions should be strengthened to improve the problem. In addition, further longitudinal studies with long period follow-up are necessary so as to better explore more on the determinants of anemia in the study subjects in resource limited settings for successful interventions. 


\section{Abbreviations}

PRISMA: Preferred Reporting Items of Systematic Reviews and Meta-Analysis; EDHS: Ethiopian Demographic and Health Survey; JUSH: Jimma University Specialised Hospital; SNNPE: Southern Nations, Nationalities and peoples of Ethiopia; USA: United States of America; WHO: World Health Organization

\section{Declaration \\ Competing interests}

The authors declare that they have no competing interests.

\section{Ethics approval and consent to participate Not applicable}

\section{Consent for publication}

Not applicable

\section{Acknowledgments}

We acknowledge Abriham Zegeye (AZ), lecturer in Debre Markos University, for supporting us in the review process.

\section{Funding}

We have not obtained any fund for this study.

\section{Availability of data and materials}

All relevant data are within the paper and its Supporting Information files.

\section{Authors' contributions}

AG: Conception of research protocol, study design, literature review, data extraction, data analysis, interpretation and drafting the manuscript. AA: Data extraction, analysis and reviewing the manuscript and quality assessment. Both the authors have read and approved the manuscript.

\section{Reference}

1. Sharman A: Anemia testing in population-based surveys: general information and guidelines for country monitors and program managers: ORC Macro; 2000.

2. WHO, Targets WGN: 2025: Anaemia Policy Brief. Geneva: World Health Organization 2014.

3. Benoist Bd, McLean E, Egll I, Cogswell M: Worldwide prevalence of anaemia 1993-2005: WHO global database on anaemia. Worldwide prevalence of anaemia 1993-2005: WHO global database on anaemia 2008.

4. University/WHO UNCsFUN: Iron deficiency anaemia. Assessment, prevention and control. A guide for programme managers (WHO/NHD/01.3). Geneva: World Health Organization;. 2001:15-31.

5. Neumann CG, Bwibo NO, Murphy SP, Sigman M, Whaley S, Allen LH, Guthrie D, Weiss RE, Demment MW: Animal source foods improve dietary quality, micronutrient status, growth and cognitive function in Kenyan school children: background, study design and baseline findings. The Journal of Nutrition 2003, 133(11):3941S-3949S.

6. Hall A, Roschnik N, Ouattara F, Touré I, Maiga F, Sacko M, Moestue H, Bendech MA: A randomised trial in Mali of the effectiveness of weekly iron supplements given by teachers on the haemoglobin concentrations of schoolchildren. Public Health Nutr 2002, 5(3):413418.

7. Tatala S, Kihamia C, Kyungu L, Svanbergrhaaa U: Risk factors for anaemia in schoolchildren in Tanga Region, Tanzania. Tanzania Journal of Health Research 2008, 10(4).

8. WHO: The global prevalence of anemia in 2011 Geneva, Switzerland: World Health Organization. 2015.

9. CSA: Central Statistical Agency of Ethiopia, 2016. Ethiopian Demographic and Health Survey [Internet]. Central Statistical Agency of Ethiopia, Addis Ababa. 2016.

10. Cameron A, Ewen M, Ross-Degnan D, Ball D, Laing R: Medicine prices, availability, and affordability in 36 developing and middle-income countries: a secondary analysis. The Lancet 2009, 373(9659):240-249.

11. Mulugeta A, Gebre M, Abdelkadir M, Stoecker BJ: Iron deficiency in adolescent school girls from tigray, northern ethiopia. The FASEB Journal 2010, 24(1 Supplement):538.534-538.534.

12. Djokic D, Drakulovic M, Radojicic Z, Radovic LC, Rakic L, Kocic S, Davidovic G: Risk factors associated with anemia among Serbian school-age children 7-14 years old: results of the first national health survey. Hippokeratia 2010, 14(4):252.

13. Simbauranga RH, Kamugisha E, Hokororo A, Kidenya BR, Makani J: Prevalence and factors associated with severe anaemia amongst under-five children hospitalized at Bugando Medical Centre, Mwanza, Tanzania. BMC Hematology 2015, 15(1):13.

14. Sudhagandhi B, Sundaresan S, William WE, Prema A: Prevalence of anemia in the school children of Kattankulathur, Tamil Nadu, India. International Journal of Nutrition, Pharmacology, Neurological Diseases 2011, 1(2):184.

15. Sanou D, Ngnie-Teta I: Risk factors for anemia in preschool children in sub-Saharan Africa. In., edn.; 2012. 
16. Koukounari A, Estambale BB, Njagi JK, Cundill B, Ajanga A, Crudder C, Otido J, Jukes MC, Clarke SE, Brooker S: Relationships between anaemia and parasitic infections in Kenyan schoolchildren: a Bayesian hierarchical modelling approach. Int J Parasitol 2008, 38(14):1663-1671.

17. Barugahara EI, Kikafunda J, Gakenia W: Prevalence and risk factors of nutritional anaemia among female school children in Masindi District, Western Uganda. African Journal of Food, Agriculture, Nutrition and Development 2013, 13(3).

18. Bobonis G, Miguel E, Puri-Sharma C: Anemia and school participation J Hum Resources 2004.

19. FMOH: Assessment of feasibility and potential benefits of food fortification in Ethiopia Addis Ababa, Ethioipia: Federal Ministry of Health. 2011.

20. Organization WH: Worldwide prevalence of anaemia 1993-2005: WHO global database on anaemia. 2008.

21. Birhanu Z, Yihdego YY, Emana D, Feyissa D, Kenate S, Kebede E, Getahun K, Yewhalaw D: Relationship between exposure to malaria and haemoglobin level of children 2-9 years old in low malaria transmission settings. Acta Trop 2017, 173:1-10.

22. Teji K, Dessie Y, Assebe T, Abdo M: Anaemia and nutritional status of adolescent girls in Babile District, Eastern Ethiopia. Pan Afr Med J 2016, 24:62.

23. Alelign T, Degarege A, Erko B: Prevalence and factors associated with undernutrition and anaemia among school children in Durbete Town, northwest Ethiopia. Archives of public bealth $=$ Archives belges de sante publique 2015, 73(1):34.

24. Mesfin F, Berhane Y, Worku A: Anemia among Primary School Children in Eastern Ethiopia. PLoS One 2015, 10(4):e0123615.

25. Assefa S, Mossie A, Hamza L: Prevalence and severity of anemia among school children in Jimma Town, Southwest Ethiopia. BMC Hematology 2014, 14(1):3.

26. Desalegn A, Mossie A, Gedefaw L: Nutritional iron deficiency anemia: magnitude and its predictors among school age children, southwest Ethiopia: a community based cross-sectional study. PLoS One 2014, 9(12):e114059.

27. Gebreegziabiher G, Etana B, Niggusie D: Determinants of Anemia among Children Aged 6-59 Months Living in Kilte Awulaelo Woreda, Northern Ethiopia. Anemia 2014, 2014:245870.

28. Gutema B, Adissu W, Asress Y, Gedefaw L: Anemia and associated factors among school-age children in Filtu Town, Somali region, Southeast Ethiopia. BMC Hematology 2014, 14(1):13.
29. Habte D, Asrat K, Magafu MG, Ali IM, Benti T, Abtew W, Tegegne G, Abera D, Shiferaw S: Maternal risk factors for childhood anaemia in Ethiopia. Afr J Reprod Health 2013, 17(3):110-118.

30. Reithinger R, Ngondi JM, Graves PM, Hwang J, Getachew A, Jima D, Ethiopia Malaria Indicator Survey Working G: Risk factors for anemia in children under 6 years of age in Ethiopia: analysis of the data from the cross-sectional Malaria IndicatorSurvey, 2007. Trans $\mathrm{R}$ Soc Trop Med Hyg 2013, 107(12):769-776.

31. Gedefaw L, Yemane T, Sahlemariam Z, Yilma D: Anemia and risk factors in HAART naive and HAART experienced HIV positive persons in south west Ethiopia: a comparative study. PLoS One 2013, 8(8):e72202. 32. Birhanu M, Asres Y, Adissu W, Yemane T, Zemene E, Gedefaw L: Hematological Parameters and Hemozoin-Containing Leukocytes and Their Association with Disease Severity among Malaria Infected Children: A Cross-Sectional Study at Pawe General Hospital, Northwest Ethiopia. Interdiscip Perspect Infect Dis 2017, 2017:8965729.

33. Geletaw T, Tadesse MZ, Demisse AG: Hematologic abnormalities and associated factors among HIV infected children pre- and post-antiretroviral treatment, North West Ethiopia. J Blood Med 2017, 8:99-105.

34. Enawgaw B, Alem M, Melku M, Addis Z, Terefe B, Yitayew G: Prevalence and associated risk factors of anemia among HIV infected children attending Gondar university hospital, Northwest Ethiopia: a cross sectional study. BMC Hematology 2015, 15(1):12.

35. Gashu D, Stoecker BJ, Adish A, Haki GD, Bougma K, Marquis GS: Ethiopian pre-school children consuming a predominantly unrefined plant-based diet have low prevalence of iron-deficiency anaemia. Public Health Nutr 2016, 19(10):1834-1841.

36. Mihiretie H, Taye B, Tsegaye A: Magnitude of anemia and associated factors among pediatric HIV/AIDS patients attending Zewditu Memorial Hospital ART Clinic, Addis Ababa, Ethiopia. Anemia 2015, 2015.

37. Taye B, Enquselassie F, Tsegaye A, Amberbir A, Medhin G, Fogarty A, Robinson K, Davey G: Effect of early and current Helicobacter pylori infection on the risk of anaemia in 6.5-year-old Ethiopian children. BMC Infect Dis 2015, 15(1):270.

38. Teklemariam Z, Mitiku H, Mesfin F: Prevalence of anemia and nutritional status among HIV-positive children receiving antiretroviral therapy in Harar, eastern Ethiopa. HIV/ AIDS (Auckland, NZ) 2015, 7:191.

39. Mahmud MA, Spigt M, Mulugeta Bezabih A, López Pavon I, Dinant G-J, Blanco Velasco R: Risk factors for intestinal parasitosis, anaemia, and malnutrition among 
school children in Ethiopia. Pathogens and Global Health 2013, 107(2):58-65.

40. Gari T, Loha E, Deressa W, Solomon T, Atsbeha H, Assegid M, Hailu A, Lindtjørn B: Anaemia among children in a drought affected community in south-central Ethiopia. PLoS One 2017, 12(3):e0170898.

41. Debasu M, Menon M, Belayneh Y, Abebe W, Jerene D, Seifu D: Anti-retroviral Treatment Related Haematological Disorders among HIV-Infected Children Attending HIV Clinic at Yekatit 12 Hospital, Addis Ababa, Ethiopia. International Blood Research \& Reviews 2015.

42. Feleke BE, Derbie A, Zenebe Y, Mekonnen D, Hailu T, Tulu B, Adem Y, Bereded F, Biadglegne F: Burden and determinant factors of anemia among elementary school children in northwest Ethiopia: a comparative cross sectional study. African Journal of Infectious Diseases 2018, 12(1):1.

43. Grimes JE, Tadesse G, Gardiner IA, Yard E, Wuletaw Y, Templeton MR, Harrison WE, Drake LJ: Sanitation, hookworm, anemia, stunting, and wasting in primary school children in southern Ethiopia: Baseline results from a study in 30 schools. PLoS Negl Trop Dis 2017, 11(10):e0005948.

44. Tiku YS, Mekonnen TC, Workie SB, Amare E: Does Anaemia Have Major Public Health Importance in Children Aged 6-59 Months in the Duggina Fanigo District of Wolaita Zone, Southern Ethiopia? Ann Nutr Metab 2018, 72(1):3-11.

45. Getaneh Z, Enawgaw B, Engidaye G, Seyoum M, Berhane M, Abebe Z, Asrie F, Melku M: Prevalence of anemia and associated factors among school children in Gondar town public primary schools, northwest Ethiopia: A school-based cross-sectional study. PLoS One 2017, 12(12):e0190151.

46. Roba K, O'Connor T, Belachew T, O’Brien N: Anemia and undernutrition among children aged 6\&ndash\&59; 23 months in two agroecological zones of rural Ethiopia. Pediatric Health, Medicine and Therapeutics 2017, 55(140):131-140.

47. Woldie H, Kebede Y, Tariku A: Factors associated with anemia among children aged 6-23 months attending growth monitoring at Tsitsika Health Center, Wag-Himra Zone, Northeast Ethiopia. Journal of Nutrition and Metabolism 2015, 2015.

48. Birmeka M, Urga K, Petros B: Assessment of Anemia and Iron Status of Primary School children aged 7-19 in Enemore-Ener and Abeshege Districts, Gurage Zone, Ethiopia. EU Nutrition 2017, 10(1):18-25.

49. Abdi Guled R, Mamat NM, Balachew T, Bakar MA, Azdie W, Assefa N: Predictors and prevalence of ane- mia, among children aged 6 to 59 months in shebelle zone, somali region, eastern Ethiopia: A cross sectional study. International Journal of Development Research 2017, 7(1):11189-11196.

50. Jemal Y, Haidar J, Kogi Makau W: The magnitude and determinants of anaemia among refugee preschool children from the Kebribeyah refugee camp, Somali region, Ethiopia. South Afr J Clin Nutr 2017, 30(1):1-6.

51. Abebe M, Alemseged F: Hematologic abormalities among children on Haart, in Jimma university specialized hospital, southwestern ethiopia. Ethiopian Journal of Health Sciences 2009, 19(2).

52. Herrador Z, Sordo L, Gadisa E, Buño A, Gómez-Rioja R, Iturzaeta JM, de Armas LF, Benito A, Aseffa A, Moreno J: Micronutrient deficiencies and related factors in school-aged children in Ethiopia: a cross-sectional study in Libo Kemkem and Fogera districts, Amhara Regional State. PLoS One 2014, 9(12):e112858.

53. Kebede SW, Beyene DA, Meshesha AG, Sinishaw MA: Two thirds of hookworm infected children were anemic at the outpatient department in Jimma Health Center, Jimma, Southwest Ethiopia. Asian Pacific Journal of Tropical Disease 2016, 6(9):691-694.

54. Adish A, Esrey S, Gyorkos T, Johns T: Risk factors for iron deficiency anaemia in preschool children in northern Ethiopia. Public Health Nutr 1999, 2(3):243252.

55. Deribew K, Tekeste Z, Petros B: Urinary schistosomiasis and malaria associated anemia in Ethiopia. Asian Pacific Journal of Tropical Biomedicine 2013, 3(4):307-310.

56. CSA: Ethiopia Demographic and Health survey 2011. Addis Ababa, Ethiopia: Central Statisical Agency. 2011.

57. CSA: Central Statistical Agency of Ethiopia, 2005. Ethiopian Demographic and Health Survey [Internet]. Central Statistical Agency of Ethiopia, Addis Ababa. 2005.

58. Engidaye G, Enawgaw B, Melaku M, Asrie F, Yalew A, Getaneh Z, Syum M: Prevalence and associated factors of anemia among preschool aged children in Menz Gera Midir Woreda. 2017, (Unpublished).

59. Melku M, Takele WW, Anlay DZ, Ekubagewargies DT, Getaneh Z, Abebe M, Abebe Z: Male and undernourished children were at high risk of anemia in Ethiopia: a systematic review and meta-analysis. Italian Journal of Pediatrics 2018, 44(1):79.

60. Gebrie A, Alebel A, Zegeye A, Tesfaye B, Ferede A: Prevalence and associated factors of overweight/ obesity among children and adolescents in Ethiopia: a systematic review and meta-analysis. BMC Obesity 2018, 5(19):1-12. 
61. Liberati A, Altman DG, Tetzlaff J, Mulrow C, Gøtzsche PC, Ioannidis JP, Clarke M, Devereaux PJ, Kleijnen J, Moher D: The PRISMA statement for reporting systematic reviews and meta-analyses of studies that evaluate health care interventions: explanation and elaboration. PLoS Med 2009, 6(7):e1000100.

62. Newcastle-Ottawa: Scale customized for cross-sectional studies. In. available from https://static-contentspringercom/esm//12889_2012_5111_ MOESM3_ ESMdoc.

63. World Health Organization: Iron Deficiency Anaemia: Assessment, Prevention and Control, a Guide for Programme Managers. Geneva : WHO. 2001.

64. World Health Organization: Hemoglobin concentrations for the diagnosis of anaemia and assessment of severity. Vitamin and mineral nutrition information system. Geneva: WHO. 2011.

65. Rücker G, Schwarzer G, Carpenter J, Schumacher M: Undue reliance on $\mathrm{I} 2$ in assessing heterogeneity may mislead. BMC Med Res Methodol 2008, 8(79).

66. Higgins J, Thompson S: Quantifying heterogeneity in a metaanalysis. Stat Med 2002, 21:1539-1558.

67. Sterne J, Egger M: Funnel plots for detecting bias in meta-analysis: guidelines on choice of axis. J Clin Epidemiol 2001, 54:1046-1055.

68. Egger M, Smith GD, Schneider M, Minder C: Bias in meta-analysis detected by a simple, graphical test. BMJ Open 1997, 315:629-634.

69. Macharia AW, Mochamah G, Uyoga S, Ndila CM, Nyutu G, Makale J, Tendwa M, Nyatichi E, Ojal J, Shebe $\mathrm{M}$ et al: The clinical epidemiology of sickle cell anemia In Africa. 2017.

70. Bello-Manga H, DeBaun MR, Kassim AA: Epidemiology and treatment of relative anemia in children with sickle cell disease in sub-Saharan Africa. Expert Rev Hematol 2016, 9(11):1031-1042.

71. Mghanga FP, Genge CM, Yeyeye L, Twalib Z, Kibopile W, Rutalemba FJ, Shengena TM: Magnitude, Severity, and Morphological Types of Anemia in Hospitalized Children Under the Age of Five in Southern Tanzania. Cureus 2017, 9(7):e1499.

72. Wander K, Shell-Duncan B, Brindle E: Lower incidence of respiratory infections among iron-deficient children in Kilimanjaro, Tanzania. Evolution, Medicine, and Public Health 2017, 2017(1):109-119.

73. Adamu AL, Crampin A, Kayuni N, Amberbir A, Koole O, Phiri A, Nyirenda M, Fine P: Prevalence and risk factors for anemia severity and type in Malawian men and women: urban and rural differences. $A m \mathrm{~J} \mathrm{He-}$ matol 2017, 15(1):12.

74. Galadanci NA, Umar Abdullahi S, Vance LD, Musa Tabari A, Ali S, Belonwu R, Salihu A, Amal Galadanci
A, Wudil Jibir B, Bello-Manga $\mathrm{H}$ et al: Feasibility trial for primary stroke prevention in children with sickle cell anemia in Nigeria (SPIN trial). 2017, 92(8):780-788. 75. Mandal A, Sahi PK: Iron deficiency anaemia among apparently healthy pre-school children in Lagos, Nigeria. Afr Health Sci 2016, 16(3):880.

76. Sokunbi OJ, Ekure EN, Temiye EO, Anyanwu R, Okoromah CAN: Pulmonary hypertension among 5 to 18 year old children with sickle cell anaemia in Nigeria. PLoS One 2017, 12(9):e0184287.

77. Stecher CW, Sacko M, Madsen H, Wilson S, Wejse C, Keita AD, Landoure A, Traore MS, Kallestrup P, Petersen E et al: Anemia and growth retardation associated with Schistosoma haematobium infection in Mali: a possible subtle impact of a neglected tropical disease. Trans R Soc Trop Med Hyg 2017, 111(4):144-153.

78. Bekele A, Tilahun M, Mekuria A: Prevalence of Anemia and Its Associated Factors among Pregnant Women Attending Antenatal Care in Health Institutions of Arba Minch Town, Gamo Gofa Zone, Ethiopia: A Cross-Sectional Study. Anemia 2016, 2016:1073192.

79. Degarege A, Yimam Y, Madhivanan P, Erko B: The relationship between helminth infections and low haemoglobin levels in Ethiopian children with blood type A. J Helminthol 2017, 91(3):278-283.

80. Feleke BE: Maternal HIV status affects the infant hemoglobin level: A comparative cross-sectional study. Medicine (Baltimore) 2016, 95(31):e4372.

81. Mulu H, Hamza L, Alemseged F: Prevalence of Malnutrition and Associated Factors among Hospitalized Patients with Acquired Immunodeficiency Syndrome in Jimma University Specialized Hospital, Ethiopia. Ethiop J Health Sci 2016, 26(3):217-226.

82. Bekele A, Tilahun M, Mekuria A: Prevalence of Anemia and Its Associated Factors among Pregnant Women Attending Antenatal Care in Health Institutions of Arba Minch Town, Gamo Gofa Zone, Ethiopia: A Cross-Sectional Study. 2016, 2016:1073192.

83. Derso T, Abera Z, Tariku A: Magnitude and associated factors of anemia among pregnant women in Dera District: a cross-sectional study in northwest Ethiopia. BMC Res Notes 2017, 10(1):359.

84. Gebreamlak B, Dadi AF, Atnafu A: High Adherence to Iron/Folic Acid Supplementation during Pregnancy Time among Antenatal and Postnatal Care Attendant Mothers in Governmental Health Centers in Akaki Kality Sub City, Addis Ababa, Ethiopia: Hierarchical Negative Binomial Poisson Regression. PLoS One 2017, 12(1):e0169415.

85. Gebre A, Mulugeta A: Prevalence of Anemia and Associated Factors among Pregnant Women in North Western Zone of Tigray, Northern Ethiopia: A 
Cross-Sectional Study. Journal of Nutrition and Metabolism 2015, 2015:165430.

86. Habte K, Adish A, Zerfu D, Kebede A, Moges T, Tesfaye B, Challa F, Baye K: Iron, folate and vitamin B12 status of Ethiopian professional runners. Nutr Metab (Lond) 2015, 12:62.

87. Ketema T, Bacha K, Alemayehu E, Ambelu A: Incidence of Severe Malaria Syndromes and Status of Immune Responses among Khat Chewer Malaria Patients in Ethiopia. PLoS One 2015, 10(7):e0131212.

88. Olani A, Habtamu Y, Wegayehu T, Anberber M: Prevalence of camel trypanosomosis (surra) and associated risk factors in Borena zone, southern Ethiopia. Parasitol Res 2016, 115(3):1141-1147.

89. Roba KT, O'Connor TP, Belachew T, O'Brien NM: Seasonal variation in nutritional status and anemia among lactating mothers in two agro-ecological zones of rural Ethiopia: A longitudinal study. Nutrition 2015, 31(10):1213-1218.

90. Schicker RS, Hiruy N, Melak B, Gelaye W, Bezabih B, Stephenson R, Patterson AE, Tadesse Z, Emerson PM, Richards FO, Jr. et al: A Venue-Based Survey of Malaria, Anemia and Mobility Patterns among Migrant Farm Workers in Amhara Region, Ethiopia. PLoS One 2015, 10(11):e0143829.

91. Abebe TB, Gebreyohannes EA, Bhagavathula AS, Tefera YG, Abegaz TM: Anemia in severe heart failure patients: does it predict prognosis? BMC Cardiovasc Disord 2017, 17(1):248.

92. Alemu M, Kinfe B, Tadesse D, Mulu W, Hailu T, Yizengaw E: Intestinal parasitosis and anaemia among patients in a Health Center, North Ethiopia. BMC Res Notes 2017, 10(1):632.

93. Ebuy Y, Alemayehu M, Mitiku M, Goba GK: Determinants of severe anemia among laboring mothers in Mekelle city public hospitals, Tigray region, Ethiopia. PLoS One 2017, 12(11):e0186724.

94. Wodajo S, Belayneh M, Gebremedhin S: Magnitude and Factors Associated With Post-Cesarean Surgical Site Infection at Hawassa University Teaching and Referral Hospital, Southern Ethiopia: A Cross-sectional Study. Ethiop J Health Sci 2017, 27(3):283-290.

95. Astatikie G, Limenih MA, Kebede M: Maternal and fetal outcomes of uterine rupture and factors associated with maternal death secondary to uterine rupture. BMC Pregnancy Childbirth 2017, 17(1):117.

96. Beyene HB, Tadesse M, Disassa H, Beyene MB: Concurrent Plasmodium infection, anemia and their correlates among newly diagnosed people living with HIV/AIDS in Northern Ethiopia. Acta Trop 2017, 169:8-13.
97. Deressa W, Loha E, Balkew M, Hailu A, Gari T, Kenea O, Overgaard HJ, Gebremichael T, Robberstad B, Lindtjorn B: Combining long-lasting insecticidal nets and indoor residual spraying for malaria prevention in Ethiopia: study protocol for a cluster randomized controlled trial. Trials 2016, 17:20.

98. Mengist $\mathrm{H}$, Taye $\mathrm{B}$, Tsegaye A: : Intestinal parasitosis in relation to CD4+T cells levels and anemia among HAART initiated and HAART naive pediatric HIV patients in a Model ART center in Addis Ababa, Ethiopia. PLoS One 2015, 10(2):e0117715.

99. American society of hematology, 2016. New Report Illustrates Persistent Global Burden of Anemia Among High-Risk Populations Including Young Children and Women [Internet]. [cited 2016 Aug 11]. Available from: http://www.hematology.org/ Newsroom/Press-Releases/2013/1326.aspx.

100. Calis JC, van Hensbroek MB, de Haan RJ, Moons P, Brabin BJ, Bates I: HIV-associated anemia in children: a systematic review from a global perspective. Aids 2008, 22(10):1099-1112.

101. Eley BS, Sive AA, Shuttleworth M, Hussey GD: A prospective, cross-sectional study of anaemia and peripheral iron status in antiretroviral naive, HIV-1 infected children in Cape Town, South Africa. BMC Infectious Diseases 2002, 2(1):3.

102. Shet A, Mehta S, Rajagopalan N, Dinakar C, Ramesh E, Samuel N, Indumathi C, Fawzi WW, Kurpad AV: Anemia and growth failure among HIV-infected children in India: a retrospective analysis. BMC Pediatrics 2009, 9(1):37.

103. Ngesa O, Mwambi H, Stoute JA: Prevalence and risk factors of anaemia among children aged between 6 months and 14 years in Kenya. PLoS One 2014, 9(11). 104. Semba R, Pee S, Kai S, Sari M, Akhter N, Bloem M: Effect of parental formal education on risk of child stunting in Indonesia and Bangladesh: a cross-sectional study. The Lancet 2008, 371(9609):322-328.

105. Webb P, Block S: Nutrition Knowledge and Parental Schooling as Inputs to Child Nutrition in the Long and Short Run. Nutrition Working Paper No 32003.

106. Mamiro PS, Kolsteren P, Roberfroid D, Tatala S, Opsomer AS, Camp JHv: Feeding practices and factors contributing to wasting, stunting, and iron-defciency anaemia among 3-23-month old children in Kilosa district, rural Tanzania. Journal of Health, Population and Nutrition 2005, 23(3):222-230.

107. Chaparro CM: Setting the stage for child health and development: prevention of iron defciency in early infancy. Journal of Nutrition 2008, 138(12):2529-2533.

108. Luo R, Kleiman-Weiner M, Rozelle S, Zhang L, 
Liu C, Sharbono B, Shi Y, Yue A, Martorell R, Lee M: Anemia in rural China's elementary schools: prevalence and correlates in Shaanxi province's poor counties. Ecology of Food and Nutrition 2010, 49(5):357-372.

109. Pasricha S-R, Black J, al SMe: Determinants of anemia among young children in rural India Pediatrics 2010, 126(1).

110. Birhane T, Shiferaw S, Hagos S, Mohindra KS: Urban food insecurity in the context of high food prices: a community based cross sectional study in Addis Ababa, Ethiopia. BMC Public Health Monograph 2014, 14(1):680. 111. Ali D, Saha KK, al PHNe: Household food insecurity is associated with higher child undernutrition in Bangladesh, Ethiopia, and Vietnam, but the effect is not mediated by child dietary diversity. J Nutr 2013, 143(12):2015-2021.

112. Osazuwa F, Ayo OM: Contribution of malnutrition and malaria to anemia in children in rural communities of Edo state, Nigeria. North American Journal of Medical Sciences 2010, 2(11):532.

113. Balarajan Y, Ramakrishnan U, Özaltin E, Shankar AH, Subramanian S: Anaemia in low-income and middle-income countries. The Lancet 2011, 378(9809):21232135.

114. Yip R, Ramakrishnan U: Experiences and challenges in developing countries. The Journal of Nutrition 2002, 132(4):827S-830S. 